above the other. Finally, the disc with three holes, one at each angle of an equilateral triángle, also within a circle of $3 \mathrm{~mm}$. diameter, is chosen. Three overlapping moons should be seen, and by rotating the disc the patient may state whether they stand with one above and two below-like A-or two above and one below-like $\mathrm{V}$.

If this test is negative it does not exclude a sound macula. But if it is positive I believe it certainly must prove that the function of the macula is present, for no such precise statements could be given without direct fixation. Simple experiments show that accurate counting without absolutely direct fixation is impossible. In private practice and with the more intelligent out-patient I have found the test very useful and easy, and when it is positive I now recommend my patient to undergo an operation with far more conviction than formerly, feeling, as I do, that there is definite clinical evidence for the soundness of the macula lutea. Before I devised this test I was never convinced. I therefore hope it will prove useful and helpful to many others.

\title{
MONOCULAR OPTIC NEURITIS
}

\author{
BY \\ Leslie Buchanan, M.D. \\ GLASGOW
}

IN August, 1919, I was asked to see a young woman who had suddenly lost the sight of the right eye. I saw her on a Monday night and she gave the following history :-

On the Saturday previous she had gone a long motor drive without any adequate preparation in the way of wraps, and was sitting with her right side to the engine. It was a very cold day and she felt numb and chilled when she reached home. She had a slight headache and retired early that evening. Next morning the headache was still present when she rose, and whilst dressing she discovered that the vision of the right eye was not so good as it had been.

The defect of vision alarmed her, and she stayed indoors all day but the sight got steadily worse, and, by evening, she could see very little with this eye. She decided to come home (from Harrogate) at once and did so next day.

On arrival she saw her medical adviser, who found that she was almost entirely blind of the right eye, and advised her to see an ophthalmic surgeon without delay. She came to me that evening and I found that perception of light, even, was abolished. 
The left eye had normal vision and the patient was certain that the right had formerly been perfect also. There was no external appearance of anything wrong. The pupil of the right eye did not react to light but did consensually. Ophthalmoscopic examination showed intense optic neuritis without haemorrhage or solid exudate; quite a typical papilloedema.

Close questioning brought out the fact that there was a feeling as of heavy pressure in the orbit, which was made worse by movement. There was also some tenderness on pressure on the eyeball. There was no paralysis of any muscle and no other symptom, such as vomiting, and I came to the conclusion that there was no cerebral cause for the neuritis. The opinion which seemed to be most reasonable was that there was a localized, nonsuppurative inflammatory focus in the orbit, and probably deeply seated in it, which was the result of exposure to cold wind and so-called rheumatic in type, and that this was the cause of the neuritis.

The patient was ordered rest in bed in a dark room, vigorous blistering of the right temple, and a mixture containing acetate and iodide of potassium and nux vomica internally.

I saw her again on September 24 having had reports by telephone in the interval, and found the vision of the right eye $4 / 9$ unaided and 4/6 aided. Her husband told me in December, 1919, that she had completely recovered and had gone to England for a month, and I have since learned that she-has remained quite well.

On May 13, 1921, I saw a young lady from the North of Scotland who averred that three weeks previously she had lost the sight of the left eye. The loss had been discovered quite suddenly on rising one morning and was associated in her mind with the fact that she had been looking at an eclipse of the sun sometime before. (She had used both eyes and had a smoked glass to protect her eyes.)

The girl had seen an ophthalmic surgeon who had recognized the neuritis but evidently considered that it was probably due to some intracranial condition, and told the patient's mother so. They then decided to have another opinion.

When I saw her the patient was only able to count fingers at six inches distance with the left eye. The right eye was normal in all respects, and the girl was perfectly healthy. Ophthalmoscopic examination showed intense papilloedema in the left eye and a normal fundus in the right. Remembering the former case, I asked if there was any history of exposure, but was unable to elicit any at that time.

The treatment ordered was the same as in the former case. A week later I saw her and found the vision $4 / 12$. There was no difference in the state of the optic nerve. At this date I was told 
that the patient remembered that a week prior to the discovery of the defect she had gone a long motor drive on a very cold day without adequate preparation in the way of wraps. She was " chilled to the bone" she told me.

On May 26 the vision was still further improved to $4 / 8$ and she went home and kept up the treatment under the care of her own doctor. I did not hear of her again until December, when she had some deafness with noises in the head on the left side. These symptoms were not due to the presence of wax in the ear because syringing did not give relief.

On April 16, 1922, I received a telegram from her father to the effect that the right eye had suddenly become blind, and asking for advice. I advised them to repeat the former treatment and come to town as soon as possible. She came to town on April 22, and was in a " home" for three weeks. R.V. counts fingers at six inches only. L.V. 4/4.

O. E. R., optic nerve deeply engorged and swollen to $1.5 \mathrm{D}$. There were no haemorrhages or other exudates. Vessels tortuous.

O. E. L., optic nerve a little pale and sharply outlined with a little pigment alteration at the other side.

The treatment was continued as before.

I had the girl carefully examined by a physician and by an aurist, but the reports were both negative as far as any cause was concerned.

The patient stated that she was sure that the sight was perfect on the night of April 14, and that it was nearly gone on the morning of April 15, and she could think of no reason in the way of exposure.

The optic nerve became more swollen and ultimately showed distinct papillitis, but never so pronounced as the left eye had shown.

In the course of four weeks she had recovered almost completely and I allowed her to return to her home, and I have learned that she is now entirely recovered.

On October 28, 1921, I was asked to see a lady who complained of loss of vision of the right eye and pain in the right side of the head of about ten days' duration. She had been kept in bed and had treatment from her doctor, but had refused to have special advice.

I found that the vision of the right eye was reduced to the ability to count fingers at two feet, whilst that of the left eye was $4 / 4$.

$\mathrm{O}$. E. showed optic neuritis of moderate degree, elevation $2 \mathrm{D}$. The history was that on October 17 she had been out and got wet and cold, and that she had neuralgic pain next day. On the 18th inst. there was a haze over the sight which increased each day till the sight got quite dim. 
Judging the condition to be the same as that of the foregoing cases, I advised the same treatment as in them. I did not see her again until December 23, when I found the vision of the right eye to be $4 / 5$, and of the left $4 / 3$. The doctor has since then reported that she has quite recovered.

The last case is that of a young girl whom I saw at the Glasgow Eye Infirmary on January 28, 1922, sent on account of blindness of the right eye. There was a history of a blow from a snowball some days before, and the girl thought that this was the cause of the blindness. The vision was reduced to nil or doubtful light perception. There was intense papilloedema, the height of the nerve being fully $3 \mathrm{D}$. Under treatment precisely similar to that of the other cases the vision gradually returned, and after two months was 4/9. The optic nerve remained congested for three -months, and then became pale, but the vision has kept up well, and on August 7, 1922, was 4/5.

These four cases have all occurred in women of under middle age, healthy and with no other symptom to indicate that there was any other cause than cold and inclement weather. No case, so far as I can recollect, which was similar to these in a man, has come under my notice, although I can be sure I had seen others in women before.

The fact that light perception was abolished or doubtful in two of the cases indicates the existence of a high degree of pressure, probably far back in the orbit. It is very interesting, therefore, that with so much disturbance of the optic nerve there was no other symptom such as would arise from interference with the function of either nerves or muscles. This was so in most of the cases recorded by Nettleship and by Jessop.

Nettleship's ${ }^{(1)}$ cases were mostly retrobulbar neuritis, but some showed marked intraocular changes also. Jessop's ${ }^{(2)}$ cases were all intraocular, but possibly began as retrobulbar cases. All may be due to the same cause only varying in position. Nettleship considered that the cases were rheumatic in origin, and Jessop that they were toxaemic. Juler ${ }^{(3)}$ recorded a case and thought that it was syphilitic in origin.

These cases are probably all acute retrobulbar neuritis to begin with, but become intraocular, but they are not the same as those which follow on catarrhs which result in infection of the ethmoidal sinuses. In the latter there is sometimes exophthalmos and at others paralysis of muscles to indicate the existence of an inflammatory focus. Cases are frequently seen also in which there is paralysis of an ocular muscle or nerve which can be attributed to no other cause than cold, and such cases yield to treatment quite the same as that used in the cases under consideration. Weeks ${ }^{(4)}$ tells us that there is a form of optic neuritis which he calls 
rheumatic, and which is due to exposure to cold. It seems, therefore, to be reasonable to assume that in these cases there is a localized fibrositis either in the nerve or round it, and that the precise position of the lesion may be the determining cause of the particular symptoms found in the case.

The prognosis seems to be distinctly favourable.

\section{REFERENCES}

1. Nettleship.-Trans. of the Ophthal. Soc. of the United Kingdom, Vol. IV, p. 186.

2. Jessop.-Trans. of the Ophthal. Soc. of the United Kingdom, Vol. XXVI, p. 170.

3. Juler.-Trans. of the Ophthal. Soc. of the United Kingdom, Vol. XIV, p. 121.

4. Weeks.-" Diseases of the Eye," 1911, p. 501.

\section{SIDEROSIS*}

GY

\section{J. Lockhart Gibson, M.D. Edin., M.R.C.S. Eng.}

BRISBANE

SIDERosis may be defined as a coloration of the eye by fine rust particles in suspension or solution in the fluids of the eye, and associated with a consequent mild but advancing inflammatory state of the uveal tract and gradual destruction of sight unless the particle of steel can be removed before the inflammatory process has advanced too far.

In a paper on the use of the Giant Magnet I contended that small particles of steel in the outside coats of the eye, not in connection with the fluids of the eye, might lie dormant and without causing irritation, because they were not apt to rust while they remained comparatively dry. But that particles of steel bathed in the fluids of the eye, especially if in the direct course of intraocular circulation were certain sooner or later to give rise to irritation because they were sure to rust, and siderosis would consequently result with its serious consequences. It is possible and perhaps even likely that those in the outer coats will also eventually cause trouble.

It has appeared to me that if this contention can be sustained it will mean that many small iron or steel fragments in the brain and other parts of the body which gave rise to few or no symptoms at first may be supposed to cause much irritation later on, perhaps after two or three years, and that wounds supposed to have become quiescent may ultimately prove most serious. I have myself had examples of small particles of steel in a lens whose capsule had closed as soon as the particle had been admitted, which, quiescent

\footnotetext{
* Read at the eleventh Australasian Medical Congress, Brisbane, 1920. .
} 